\title{
POR QUE AGOSTINHO NÃO É UM FILÓSOFO MEDIEVAL (E POR QUE É IMPORTANTE COMPREENDER ISSO)
}

\author{
Ernesto Perini-Santos* \\ epsantos@fafich.ufmg.br
}

RESUMO Agostinho é um filósofo medieval ou um filósofo antigo? Alguns autores defendem que ele é um filósofo medieval porque desempenhou um papel central na absorção da filosofia grega num quadro teórico cristão. Sua importância na constituição do pensamento cristão é sem dúvida enorme, mas não fornece um bom argumento para uma tese sobre a periodização em história da filosofia. Agostinho é um filósofo antigo porque pertence ao mundo antigo, não ao mundo medieval, e esta fronteira histórica corresponde à queda do Império Romano do Ocidente. Os fatos que parecem sustentar ambas as respostas são bem conhecidos, o que deve ser ajustado, portanto, é a pergunta: o que explica modificações amplas pelas quais a filosofia passou ao longo tempo? Os mecanismos envolvidos nessas modificações podem ser compreendidos uma vez que vemos a filosofia como parte da cultura, e parece claro haver uma ruptura muito importante entre os séculos $V$ e XI. Mais interessante do que saber em que periodo classificar Agostinho é podermos colocar perguntas mais explicativas sobre essas mudanças: como tradições filosóficas nascem e morrem? Minha proposta é utilizar o modelo da epidemiologia da cultura, de Dan Sperber, para responder esta pergunta.

Palavras-chave Agostinho, historiografia filosófica, filosofia medieval. 
ABSTRACT Is Augustine a medieval or an ancient philosopher? Some authors advogate that he is a medieval philosopher because he played a crucial role in the absorption of Greek Philosophy into the Christian theorethical framework. While this is certainly true, it does not give us a proper way to understand the periodization of the history of philosophy. Augustine is an ancient philosopher because he belongs to the ancient world, and not to the medieval world, and the frontier is roughly established by the fall of Western Roman Empire. The facts that seem to ground both answers are well known, we should therefore have a better grasp of the question: what explains the large changes of philosophy along its history? These changes may be better understood once we see philosophy as part of the culture, and it seems clear that there are huge cultural differences between the $5^{\text {th }}$ and the $11^{\text {th }}$ centuries. More interesting than classifying Augustine as a medieval or as an ancient author, however, is asking better questions concerning the history of philosophy: how do philosophical traditions born and die? My proposal is to use Dan Sperber's model on the epidemiology of culture to answer this question.

Keywords Augustine, historiography of philosophy, medieval philosophy.

\section{I}

A tese é simples: Agostinho é um filósofo antigo, não um filósofo medieval, porque ele pertence ao mundo antigo. Ela é estabelecida por fatos bem conhecidos, mesmo se algum cuidado na sua apresentação é necessário. Ela é suposta por algumas das principais histórias da filosofia medieval recentes, que começam sua narrativa depois de Agostinho, ${ }^{1}$ mas não por todas. ${ }^{2}$

1 "A filosofia medieval surge depois do declínio da Grécia e da Roma antigas, quando novas culturas começam a produzir trabalhos de filosofia que, ao mesmo tempo, são inspirados pelo legado antigo e respondem a novas circunstâncias culturais e religiosas. Existe hoje um certo consenso acerca de quando e onde localizar os inícios da filosofia medieval, compreendida como um projeto de pesquisa filosófica independente: ela começa em Bagdá, no meio do século VIII, e na França, na corte itinerante de Carlos Magno, no último quarto do século VIII”. Pasnau, 2010, 1. Pasnau acrescenta em nota a este texto: "Tradicionalmente, Agostinho (354-430) e Boécio (ca. 475-526) eram incluídos no currículo medieval, mas eles são claramente parte do mundo antigo. Esta tradição tem sua origem em parte na antiga tendência de classicistas de negligenciar a Antiguidade tardia, e em parte na antiga tendência de medievalistas de assimilar a filosofia medieval à filosofia cristã”. De Libera, 1993; Marenbon, 1983; Flasch, 1992 (1987); Gauvard, Claude, Libera e Zink, 2002.

2 Kenny, 2008 (2005); McGrade, 2003; Lagerlund, 2011; Martin, 1996. 
Não é simples encontrar uma defesa claramente articulada de uma resposta ou outra. Talvez a razão deste fato venha da irrelevância para a compreensão de Agostinho da resposta a esta questão: sua importância reside em preocupações historiográficas, não na interpretação de teorias filosóficas e, em particular, uma ou outra escolha não afeta a compreensão de Agostinho ele mesmo.

É possível, no entanto, encontrar argumentos a favor da tese que situa Agostinho entre os medievais. Steven Marrone a defende num capítulo do "Cambridge Companion to Medieval Philosophy". ${ }^{3}$ Outra linha argumentativa se deve a Peter Seele, que situa Agostinho entre a Antiguidade e a Idade Média. Segundo Marrone, Agostinho é responsável pela "acomodação" entre o pensamento cristão e a filosofia antiga, que é o que caracteriza na filosofia medieval. ${ }^{4}$ A hipótese de Seele é teoricamente mais ambiciosa: o autor aplica o conceito de "limiar de épocas" (Epochenschwelle) de Hans Blumenberg à transição entre a Antiguidade e a Idade Média. A mudança de época em questão, associada tanto à mudança de paradigmas de Kuhn quanto a mudanças institucionais, explica-se por uma crise de traços fundamentais na cultura, que é resolvida por uma ampla reconfiguração na qual Agostinho desempenha um papel central.

Vou partir da crítica à tese mais simples de Marrone. Este primeiro movimento permitirá o reconhecimento dos fatos pertinentes, acerca dos quais não há realmente controvérsia, e o estabelecimento de explananda que parecem razoáveis para a periodização em história da filosofia aplicados à separação entre as filosofias antiga e medieval. À luz deste percurso inicial, examinarei as consequências da proposta de Blumenberg-Seele para a divisão entre os mundos antigo e medieval e, finalmente, farei outra proposta para um quadro teórico que me parece mais adequado para a periodização em história da filosofia. Minha sugestão é a utilização da epidemiologia cultural proposta por Dan Sperber, que permite o acolhimento de explananda que podem ser motivados de maneira independente e coloca a história da filosofia no quadro da história de mudanças culturais, da qual ela é apenas uma parte. Há uma tese mais geral e mais neutra, que não envolve a aceitação das teses da epidemiologia cultural: que Agostinho seja um filósofo medieval segue-se da aceitação da filosofia como parte da cultura e de haver uma enorme diferença cultural entre os séculos IV e V e os séculos XI-XIV. 


\section{II}

Marrone divide a filosofia medieval em três fases: a primeira entre o século II (ou antes) ao século V. A segunda começa no século V e se estende até o século XI, a terceira vai da segunda metade do século XI e até o século XIII, ou talvez o século XIV. A segunda fase é um hiato de seis séculos de "dormência", 5 depois deste período a filosofia surge como um novo modelo, com grande ênfase na lógica. A mera descrição da proposta deve mostrar que há um problema nesta periodização - o hiato de seis séculos parece grande demais para o período de onze séculos.

As teses de que a filosofia medieval seja o resultado da "síntese" entre a filosofia antiga e as tradições judaica e cristã, e que esta síntese tenha sido feita por Agostinho, são o ponto central da classificação do bispo de Hipona como um filósofo medieval. ${ }^{6}$ Marrone defende explicitamente o primeiro componente deste argumento:

[...] o que conhecemos como filosofia medieval surgiu no Império Romano tardio de uma surpreendentemente completa acomodação mútua entre a crença cristã e o pensamento clássico. (Morrone, 2003, p. 10)

Esta descrição não está correta. Inicialmente, os adjetivos e o advérbio escolhidos por Marrone não se justificam. As influências não parecem ser mútuas, ou pelo menos não são simétricas. A filosofia antiga forneceu o quadro teórico que foi assumido pelas religiões monoteístas e não é claro que tenha ocorrido o movimento no sentido inverso. ${ }^{7}$ Além disso, a associação entre a filosofia antiga e o pensamento cristão não se fez apenas em termos teóricos, mas em função das estruturas de poder que também são assimétricas. ${ }^{8}$

Não há sentido tampouco em se falar em "acomodação completa": nos dois polos apontados por Marrone, há quem não aceite as teses "acomodadas",

5 Marrone, 2003, p. 16.

6 Martin dá uma formulação típica desta compreensão: "Foi Agostinho que realizou uma síntese triunfal do ensinamento grego da filosofia antiga e das tradições judaicas e cristãs que ele também aceitou, e assim estabeleceu o padrão para mil anos de desenvolvimento intelectual: um feito sem paralelo no Ocidente para alguém que se dizia uma mera autoridade humana" (Martin, 1996, p. 10).

7 "Procuramos mostrar como a filosofia grega atingiu sua fase última e, provavelmente, mais influente, aquela que historiadores da filosofia antiga chamam Neoplatonismo, e como ela foi assumida e adaptada de diferentes maneiras, de acordo com os propósitos de cada um, por judeus, cristãos e muçulmanos" (Pasnau, 2010, p. 1). "Mesmo se, de um ponto de vista técnico, suas formas são amplamente tomadas, como uma simples transposição, desta tradição clássica cuja vitalidade procuramos destacar, devemos ver que esta cultura cristã também é, como sua homóloga judaica, uma cultura de inspiração e finalidade essencialmente religiosas" (Marrou, 1977, p. 71). Ambas as citações indicam que a contribuição teórica foi da cultura grega para as culturas monoteístas, e não no sentido inverso.

8 Sobre este ponto, ver Veyne, 2007. 
cada passo envolve escolhas teóricas que deixam outras alternativas de lado. ${ }^{9}$ Finalmente, na medida em que a acomodação não é nem mútua, nem completa, não parece fazer sentido dizer que há nela algo de "surpreendente": de fato, não parece haver nada de extraordinário na afirmação de que, quando duas (ou mais) tradições diferentes se encontram num mesmo espaço, haja tanto pessoas dispostas a adotar uma mescla de cada uma das tradições envolvidas quanto aquelas inclinadas antes a rejeitar aquela que não é a sua. Esta associação é tanto mais provável quando existem razões para a adoção de uma tradição nova. ${ }^{10}$

A infeliz escolha das qualificações por Marrone não são, no entanto, o principal problema. O ponto central é que as relações entre a filosofia antiga não cristã e o cristianismo nos séculos III-V e nos séculos XI-XIII são muito diferentes. A proximidade entre o cristianismo e os diferentes tipos de filosofia nos séculos III-V é sem dúvida importante, mas é falsa para o período que começa no XI (não é muito claro por que Marrone escolhe os séculos XI e XIII como limites da filosofia medieval, mas isso não modifica meu argumento): não há então convergência entre cristianismo e qualquer outra doutrina, porque não há outra doutrina disponível - como diz G. R. Evans, ser filósofo não era, no século XI, "uma alternativa prática a ser cristão". ${ }^{11} \mathrm{Na}$ Antiguidade tardia,

9 Que a acomodação não seja completa aparece na seguinte descrição das diferentes atitudes de neoplatônicos em relação ao cristianismo: "[...] neo-platônicos atenienses seguiam a tradição de Jâmblico de praticar ritos mágicos associados aos Oráculos Caldeus; eles incorporaram a teoria da simpatia cósmica sobre a qual a Teiurgia se funda em seu sistema filosófico e a viam como um caminho possível para a união com o divino. [...] Amônio, no entanto, nada diz sobre a Teiurgia e os Oráculos Caldeus. Isto pode ser o reflexo de suas atitudes pessoais, claro, mas eu acho provável que seu acordo com Patriarca era um acordo para manter o silêncio sobre aquilo que os cristãos veriam como uma mágica perniciosa. Damáscio teria desprezado este acordo do mesmo modo que desprezaria a restrição de se ensinar Platão. Se isto estiver certo, Amônio fez concessões ao Cristianismo em um domínio importante. [...] Olimpiodoro era um pagão. Ele defendia a eternidade do mundo e acreditava na reencarnação. Ele também menciona o culto de imagens, a Teiurgia e os Oráculos Caldeus. Como Proclo e Damáscio, ele faz por vezes alusões à religião cristã dominante em termos velados e pouco respeitosos. Sua atitude em relação ao Cristianismo é no entanto mais conciliatória e discreta do que a de Proclo e Damáscio. [...] Na Alexandria do século VI, paganismo e Cristianismo parecem coexistir confortavelmente [...]" (Sheppard, 2000 , p. 848-850). A história posterior da filosofia medieval mostra que sempre houve restos e conflitos na associação entre duas tradições, ou antes entre as muitas tradições que informam a filosofia praticada nos século XIII; para uma história de alguns destes conflitos, ver De Libera, 1991.

10 Paul Veyne descreve do seguinte modo a adoção do cristianismo na Antiguidade tardia: "Parece claro que a cristianização das massas não se deveu nem à perseguição, nem, na maioria das vezes, à evangelização, mas a um conformismo que lhes foi ditado por uma autoridade agora reconhecida, a dos bispos: o peso de uma autoridade moral e o dever virtuoso de 'fazer como todo mundo'" (Veyne, 2007, p. 201). A pergunta a ser feita aqui é: o que há de surpreendente nesta difusão?

11 "Cristãos que falavam de 'filosofia' não tinham em mente a mesma coisa no século $V$ e mil anos depois. Leitores medievais utilizavam em boa medida os mesmos textos que já eram vistos como clássicos sobre o tema nos tempos de Agostinho. Mas eles não viviam mais num mundo no qual 'ser filósofo' era uma alternativa prática a ser cristão, e no qual era possível encontrar e conversar com homens que tinham feito esta escolha. A filosofia na Idade Média era em grande medida um estudo acadêmico, com seu alcance confinado sobretudo aos temas e tópicos acerca dos quais os livros antigos que restavam traziam algum 
inversamente, cristãos e pagãos conviviam. Agostinho ele mesmo percorreu diferentes filosofias até se decidir pelo cristianismo, que era uma das opções abertas a ele. Nenhuma dessas figuras pode ser encontrada nos séculos XIXIII, o percurso agostiniano não seria possível nos séculos XII ou XIII. ${ }^{12}$

A descrição mesma da "acomodação" entre pensamento cristão e grego é enganadora, já que esta dinâmica inclui os pensamentos judaico e islâmico - o que torna os adjetivos "mútua", "completa" e "surpreendente" ainda mais suspeitos. Se essas três religiões são parte da dinâmica à qual Marrone faz alusão, elas não o fazem num único espaço, nem num único tempo, o que as torna pouco aptas a servir de critério à periodização filosófica. Vamos partir de outra pergunta: como podemos comparar a primeira e a terceira fases da filosofia medieval segundo Marrone?

\section{III}

A queda do Império Romano do Ocidente, no último quarto do século $\mathrm{V}$, não marca uma ruptura absoluta do modo de vida romano das elites. Ao contrário, reis Godos, Lombardos e outros pensavam dever governar à maneira dos romanos e, para isso, empregavam precisamente a elite letrada romana. Isso garante alguma continuidade da atividade letrada sob a dominação dos "bárbaros". Este é o caso, por exemplo, de Boécio, um aristocrata romano cristão que teve um alto cargo administrativo no governo do ostrogodo Teodorico. No entanto, nas palavras de Chris Wickham, "a cultura secular das elites do Império Romano deixou de ser uma marca de status. [...] conhecer Virgílio e outros autores clássicos seculares de cor, ser capaz compor versos e escrever numa prosa complexa [...] deixa de ser importante" (Wickham, 2009, p. 106). Uma consequência interessante desta dispersão cultural é

ensinamento. Era uma disciplina viva e em expansão, mas não mais do mesmo modo que havia sido nos primeiros séculos cristãos, quando escolas e facções rivais surgiam e morriam, e havia sempre tentativas de novas permutações de idéias platônicas, aristotélicas e estóicas. Isto não quer dizer que os medievais não tenham feito um trabalho novo e significante em filosofia. Mas eles os fizeram de maneira pontual, avançando fronteiras em pontos particulares, e não como um modo de criar novos sistemas de vida e de pensamento" (Evans, 1993, p. 3).

12 "Esta concepção da filosofia como uma atividade abarcando tudo, preocupando-se com todas as coisas relevantes para a realização do último propósito da vida humana, tem ela mesma sua origem na Antiguidade. Agostinho refere-se ao manual de filosofia de Varrão, hoje perdido, no qual foram identificadas 288 'filosofias' diferentes, distinguidas precisamente pelos tipos de resposta possíveis à questão sobre como se chegar à vida feliz. Todas concordavam com o propósito e divergiam entre si apenas quanto aos meios pelos quais podia ser atingido. Segundo este uso, o Cristianismo era claramente uma 'filosofia', e nos trabalhos escritos na época de sua conversão e imediatamente subsequentes, Agostinho interpretou sua conversão como o resultado de sua busca pela sabedoria e frequentemente diz de ter chegado ao 'porto da filosofia'” (Markus, 1967, p. 344). 
desaparecimento de controvérsias doutrinais, que tanto marcaram a época e a vida de Agostinho. ${ }^{13}$ A cultura letrada desaparece em todos os estratos sociais, assim como a motivação mesma para se aprender a ler e a escrever. ${ }^{14}$ $\mathrm{O}$ que começa no século $\mathrm{V}$ não é um período durante o qual assistimos a uma renovação progressiva da atividade filosófica, mas um período no qual esta atividade virtualmente desaparece. Esta descontinuidade explica alguns traços importantes da filosofia dos séculos XI-XIII (assumindo que estes são os séculos da filosofia tipicamente medieval, como sugere Marrone).

1. O primeiro destes traços é o lugar da filosofia na cultura. Inicialmente, a rarefação da atividade filosófica no período de "dormência" é tal que, ao ressurgir, ela pode ser localizada em lugares específicos, sempre, ou quase sempre ligados a uma instituição, a Igreja: em mosteiros ou em escolas associadas a catedrais ou a cortes, etc. As universidades, que desempenham um papel central a partir do século XIII, são um desenvolvimento desta história de organização institucional da transmissão do saber. ${ }^{15}$ Nada disso é verdadeiro no século IV, tanto pela relativa diversidade de saídas para aqueles que têm uma formação filosófica, que revela uma presença mais diversa da filosofia na sociedade (advogado, professor etc.), ${ }^{16}$ como pela ausência de

13 "Na Espanha, a ortodoxia religiosa ainda era importante, como a perseguição aos judeus no final do século VII mostra. Os bispos espanhóis perseguiram até os Priscilianistas, uma seita de muito pouca importância. [...] Mas heresias não voltaram a aparecer mesmo na Espanha até o final do século VIII, e na França, e mais tarde na Inglaterra, a controvérsia religiosa raramente estava ligada a questões doutrinais. Apenas a data da páscoa trazia dificuldades, e assim mesmo apenas nas Igrejas da Irlanda e do País de Gales [...] A falta de discussões teológicas intensas neste período provavelmente reflete uma massa crítica menor de homens da Igreja educados. [...] A fragmentação política da Igreja ocidental e a ausência de heresias estavam conectadas: as pessoas simplesmente não tinham informações regulares sobre o que estava acontecendo fora de seus próprios circuitos locais e regionais" (Wickham, 2009, pp. 172-174).

14 "Reis e papas recorriam frequentemente ao passado romano, e os aristocratas sub-romanos que os rodeavam continuavam a antiga tradição literária. Ainda assim, por trás desta fachada de continuidade, muito havia mudado. Ao longo do século $\mathrm{V}$, a maior parte das grandes escolas urbanas de gramática e retórica parecem ter desaparecido. [...]. Em torno de 500, as escolas de Autun e Bordeaux desaparecem de vista. Em outros lugares da Gália, não há registros senão de um ou outro orador isolado. Na medida em que sobrevive, a oratória aparece em homilias de clérigos que cultivam deliberadamente um estilo literário simples, como o Bispo Cesário de Arles (502-542), respondendo aos padrões do tempo. [...] Certamente as instituições que empregavam os oradores treinados estavam elas mesmas desmoronando. Com o declínio e o colapso da corte imperial e com a ruptura do império, houve uma ruptura dos empregos governamentais, trabalhos que requeriam habilidades retóricas. Como resultado, não houve mais incentivo para o domínio das regras da retórica latina. Embora a educação ainda continuasse em algumas famílias, ela foi cada vez associada à igreja. A leitura era ensinada principalmente em paróquias, com a Bíblia, especialmente o livro dos Salmos. O ensino mais avançado podia ser encontrado em torno dos bispos e, cada vez mais, de monastérios" (Wood, 2001, p. 175).

15 Ver Verger, 1997, pp. 43-59.

16 Como Moorhead observa em sua apresentação da vida de Boécio, "como as maneiras de se compreender o tema da filosofia e sua prática propostos por Agostinho sugerem, as preocupações da filosofia na sociedade do mundo antigo eram mais amplas do que elas serão em seguida na tradição ocidental" (Moorhead, 2009, p. 23). 
algo análogo à centralização institucional da difusão da filosofia, como foi o caso das universidades a partir do século XIII.

2. Associada a esta rarefação está a concentração quase exclusiva da atividade filosófica, como da atividade letrada em geral, em torno da Igreja. Mesmo se isso não vale em geral, ${ }^{17}$ esta concessão pouco muda o quadro geral: a filosofia não se apresenta como uma alternativa à doutrina da Igreja. Este é um traço que opõe o lugar que a filosofia pôde ocupar nas vidas atribuladas de Agostinho e Boécio e nas histórias de filósofos tão diferentes quanto Abelardo e Tomás de Aquino: a estes não se apresentou uma alternativa a ser cristão e mesmo os modos como se devia ser cristão eram muito mais restritos do que o que se apresentava na Antiguidade tardia, caracterizada pelos extraordinários alcance e variedade do que é chamado de maneira vaga "Platonismo Cristão" (Armstrong, 1967, p. 8). É claro que Abelardo e Tomás conheceram polêmicas doutrinárias, mas dentro de um quadro institucional que regulava a forma mesma da discussão. Não há, sobretudo, no século XI ocidental, alguém que se torne cristão depois de ter percorrido outras alternativas filosóficas, i.e., depois de ter sido não cristão, como é precisamente o caso de Agostinho. Este fato é fundamental na prática filosófica. Não há escolha pelo cristianismo e, mesmo se há, dentro de certos limites, diferentes opções teóricas, ser cristão é um elemento fixo. ${ }^{18}$

3. Um outro traço importante que se explica pela descontinuidade entre os séculos V e XI é o desenvolvimento ritmado pela tradução de textos gregos e árabes. ${ }^{19} \mathrm{O}$ que importa aqui não é o papel da atividade do comentário nem

17 Os príncipes laicos, "preocupados em afirmar a dimensão soberana de seu poder, não podiam permanecer inteiramente alheios aos problemas da educação. É verdade que Frederico II foi o único a criar uma instituição de ensino superior da qual a Igreja foi inteiramente afastada, o studium generale de Nápoles (1224) - instituição que teve, de resto, um destino medíocre. Em todos os outros lugares, os príncipes respeitaram o antigo monopólio da Igreja em questões de ensino e o direito do papa de atribuir a certas escolas de seu reino privilégios excepcionais" (Verger, 1997, p. 54).

18 "É difícil saber ao certo quanto das crenças e práticas pagãs sobreviveram no ocidente cristão. Elas persistiram em algumas regiões recentemente convertidas, como a Noruega e a Hungria, mas nas áreas nas quais o cristianismo estava bem estabelecido, o paganismo parece ter se fundido no folclore [...] Embora a imaginação das pessoas no ocidente cristão possa ter guardado uma dimensão pagã, todas as evidências sugerem que, em torno do século XI, a lgreja tinha ganhado a batalha intelectual e que, em termos gerais, todo mundo aceitava a visão de mundo cristã" (Hamilton, 2008a, p. 500). É claro que houve heresias, como a dos bogomilos e a dos cátaros, que tiveram sua importância na história medieval, mas elas não são parte das possibilidades abertas aos filósofos medievais - as ordens mendicantes, tão importantes na história das universidades medievais, têm o papel de inquisição em relação aos cátaros; ver Hamilton 2008b, pp. 172-174. Devemos contrastar aqui o percurso agostiniano, que passa pelo maniqueísmo antes de chegar ao cristianismo, e a marginalidade dos cátaros, que tinham uma doutrina similar, nos séculos XII-XIV. Note-se ainda que estes casos são mais versões dissidentes do cristianismo do que propriamente alternativas a ele.

19 "A Idade Média aqui apresentada ainda não conhece as distinções modernas entre 'escolástica', 'mística' e 'filosofia'; o movimento das ideias não está separado da organização da vida intelectual; o ritmo do 
a centralidade da materialidade dos textos no desenvolvimento das discussões filosóficas, já cruciais na Antiguidade tardia, mas o fato de a progressão da filosofia se explicar pelo ritmo de entrada dos textos. Isto é claro no modo como desenvolvimentos teóricos se organizam em torno dos textos aristotélicos traduzidos e comentados por Boécio e na importância da chegada massiva das traduções de Aristóteles e comentadores entre o fim do século XII e o início do século XIII. Esta observação nos lembra do caráter local da periodização: os textos de Aristóteles traduzidos do grego para o latim chegam de algum outro lugar e já haviam sido traduzidos para outras línguas. Não há nada desta ordem no século V, nem, claro, nos séculos anteriores, porque há uma continuidade muito maior na transmissão da filosofia de Platão e Aristóteles a Proclo e Siriano..$^{20}$

4. A dinâmica linguística é ela mesma muito diferente nos séculos $\mathrm{V}$ e XI. Aqueles que escreveram filosofia no ocidente entre os séculos XI e XIII não tinham o latim como língua materna, diferentemente de Agostinho. Além das claras diferenças no latim entre os séculos V e XI, há uma dinâmica linguística própria do ocidente medieval latino, entre a língua referencial, as línguas locais e as línguas da corte, que dá não apenas a forma específica na qual boa parte da produção filosófica medieval se faz, mas também resulta em percepções diferentes acerca dos diferentes domínios linguísticos. ${ }^{21}$

pensamento segue o ritmo das traduções e introduz nesse tempo a sua própria cadência; seus pensadores são seres vivos que lêem, escrevem e ensinam em mundos definidos” (De Libera, 1990 (1989), p. 8).

20 "É útil ter alguns indicadores, mesmo se eles demandarem alguma correção, como acontece a indicadores. O século e meio entre a morte de Plotino (270) e o meio do reinado de Constantino será dominado pelas figuras de Porfírio e do sírio Jâmblico (morto em 326). Pupilos de Jâmblico continuaram a ensinar na Síria, mas quase não há mais traço de sua contribuição para a filosofia; provavelmente eles não têm contribuição alguma. Vamos assim a Atenas, onde também era muito influente. A Escola de Atenas tinha uma história contínua deste Platão, mas nada sabemos de sua filosofia de algum tempo antes do grande século do Neoplatonismo ateniense. Este começa com um homem chamado Plutarco em torno do final do século IV, mas consiste substancialmente no trio Siriano, Proclo e Damáscio. Na verdade, seu ensinamento parece estático o bastante para ser examinado apenas na forma como aparece em Proclo, de quem pelo menos quatro das principais obras sobreviveram. Sua influência parou quando Justiniano fechou a Escola em 529, mas teve uma volta inesperada, pois a filosofia por trás dos comentários aristotélicos de Simplício na década de 530 vem de Proclo" (Lloyd, 1967, p. 272). Não há uma história contínua ligando o final da Antiguidade Tardia ao século XI, o início da última fase da filosofia medieval segundo Marrone.

21 "[Isidoro de Sevilha] descreve no início do livro IX a evolução do latim de um modo compatível com nossa visão científica. A língua é sucessivamente arcaica sob Janus e Saturno, latina sob os reis, romana sob a República e Augusto, e enfim mista depois da extensão do Império [...] Esta capacidade de modelização decorre de duas vantagens que não terão seus sucessores: o acesso a obras lingüísticas e gramáticas perdidas nos séculos posteriores e a possibilidade de projetar a variação dos diversos estados do latim ordenados cronologicamente na sua percepção dos registros sociolingüísticos em uso na sua época. Nesta ótica, a língua fixa da latinidade clássica [...] aparece como a norma imposta no apogeu de uma romanidade que continua sem verdadeira interrupção através do latim degradado dos povos do imperium visigodo. Bem diferentes são os problemas que encontram os teóricos dos séculos XIII e XIV. A variedade infinita dos dialetos locais e suas elaborações nas cortes, agora concebidas como línguas autônomas, se opõe de maneira muito brutal à fixidez do latim, do grego e do hebreu para que não se crie uma dissociação conceitual. Os primeiros são pensados sob o signo da dispersão segundo as categorias 


\section{IV}

Todos esses fatos são bem conhecidos. O problema reside em saber se eles têm alguma importância para a periodização filosófica. Minha primeira sugestão é que a periodização filosófica deve nos permitir classificar a atividade de filósofos ao longo do tempo de maneira informativa em duas dimensões: (a) as semelhanças e diferenças nos modos como se faz filosofia e (b) uma narrativa da constituição destes modos. Sobre (a), os quatro pontos expostos acima constituem diferenças cruciais entre a atividade filosófica nos séculos II-VI e nos séculos XI-XIII: (i) o lugar da filosofia na cultura, (ii) sua relação com a religião, (iii) o modo como seus temas de estudo evoluem e (iv) o modo como se constrói e é percebida a língua na qual a filosofia se escreve. O segundo ponto também é importante: é claro que não podemos exigir que a classificação em períodos resulte em características absolutamente uniformes, o que é provavelmente verdadeiro de qualquer classificação. $\mathrm{O}$ que me parece razoável esperar de uma classificação em períodos históricos é que ela nos forneça razões propriamente históricas para as mudanças. Existe, por exemplo, uma narrativa contínua, i.e., com transformações progressivas, de como as universidades surgiram a partir de um crescimento na cultura letrada a partir do século XI. Há também uma história de seu surgimento como um exemplo de organização corporativa de uma profissão e da dinâmica própria que leva da busca de estabilidade e liberdade diante de poderes locais junto a instâncias mais amplas, em particular o Papado, à restrição ainda maior de seu desenvolvimento por estas mesmas instâncias. ${ }^{22}$ Ambas as histórias são parte da explicação de (i)-(iv). Não há uma dinâmica com este grau de continuidade ligando o século $\mathrm{V}$ ao século XI - ao contrário, há uma ruptura nos traços identificados em (i)-(iv).

É claro que existem continuidades entre os séculos V e XIII e rupturas entre os séculos XI e XIII. Pode-se, sobretudo, construir outras narrativas, a partir de outros interesses, que tenham resultados distintos. Alain de Libera, por exemplo, identifica a "episteme alexandrina" com o conjunto de problemas em torno da questão dos universais delimitado por sua interpretação por Alexandre de Afrodísia, ou, mais precisamente, pela sua transmissão textual,

cambiantes de habitus sociais e físicos associados à influência do meio natural submetido às leis de uma física ptolomaica. Eles são naturalizados. As línguas da Cruz, por outro lado, são postas no centro de um conjunto de falares que, incluindo o árabe e o aramaico e talvez outros falares misteriosos, estão mais no domínio do artificial. Elas resultam do trabalho de um artesão, divino ou divinamente inspirado, que fixou suas leis uma vez por todas, de maneira que elas têm virtudes que as colocam ao abrigo da corrupção humana" (Grévin, 2012, pp. 131-132).

22 Ver, por exemplo, Verger, 1998. 
do século II ao século XII. ${ }^{23}$ Este recorte não corresponde a limite algum do tipo discutido aqui, nem é esta a intenção de De Libera; trata-se antes de identificar um conjunto de problemas específicos e a história de sua transmissão através de textos interligados, de uma rede textual, segundo sua expressão. Ainda mais central para nossos propósitos, a "Cambridge History of Later Greek and Early Medieval Philosophy" se dedica precisamente a descrever como o pensamento clássico foi absorvido pelas religiões monoteístas - existe, portanto, uma narrativa coerente a ser oferecida sobre este problema preciso. Segundo o editor deste volume, divisões da história da filosofia são arbitrárias e este problema específico fornece uma unidade suficiente para uma narrativa longa e com alguma unidade. ${ }^{24}$ Não me parece que o termo "arbitrário" seja o mais adequado, se ele indica que qualquer divisão é possível; talvez seja melhor dizer que há uma pluralidade de narrativas possíveis segundo o que se pretende explicar, com as diferentes divisões que delas resultam. Devemos nos perguntar então se existe uma narrativa central que sirva como base para a periodização da atividade filosófica de uma dada época. A suspeita, claro, é que cada interesse levará uma narrativa particular e que não há razão para se propor uma narrativa mestra. ${ }^{25}$

A pista vem, mais uma vez, de De Libera. Desde "La Philosophie Médievale" (1993; 1998), De Libera tem insistido sobre a importância da compreensão da história da filosofia como um amplo movimento de transferência cultural. O elemento central está no fato de a filosofia ser uma parte da cultura, a história de suas continuidades e rupturas é parte da história mais geral, da história dos livros e do público que por eles se interessa, das instituições que a transmitem, da história das línguas, da história política e econômica etc. Esta compreensão leva a uma outra visão do encontro entre a filosofia antiga e a filosofia medieval:

[...] como se fez o trabalho medieval sobre o arquivo, ou, se se preferir, como a Idade Média encontrou a Antiguidade? Este é o terreno no qual se situa o problema das permanências, recorrências e esquecimentos: não o terreno de uma metafísica ou de uma teologia da história, mas de uma teoria da condição textual. (De Libera, 1999, p. 11)

23 Cf. De Libera, 1999.

24 "Todas divisões da história da filosofia em períodos são em alguma medida arbitrárias, mas os pontos escolhidos para concluir as últimas partes deste volume nos pareceram bons pontos de paradas, e o pensamento coberto no volume como um todo nos parece ter um certo grau de unidade, como está mais amplamente explicado no capítulo introdutório" (Armstrong, 1967, p. xiv).

25 Devo esta observação a Claude Panaccio. 
Tudo isso é provavelmente evidente. No entanto, mais uma vez, os fatos que separam a Antiguidade tardia do período medieval são também conhecidos. A narrativa central da história da filosofia é aquela que a conecta com outros aspectos da história da qual faz parte. Ao puxar os fios da condição textual da filosofia, encontraremos tudo o que separa economicamente, politicamente, culturalmente, a Antiguidade tardia da Idade Média, desde a diminuição da difusão da escrita ${ }^{26}$ até a redução no número de bibliotecas. Sobre este último ponto, Lionel Casson descreve a situação na Itália do seguinte modo:

Nos prósperos dias do Império Romano, a Itália tinha bibliotecas municipais distribuídas em toda península; estas bibliotecas desapareceram quando, cidade após cidade, ela caiu sob o domínio ostrogodo no século VI. [...] Na época de Augusto e Trajano, [Roma] tinha bibliotecas públicas esplêndidas, tinha uma população de mais de um milhão de habitantes; nos sangrentos anos [de Justiniano (527-565)], sua população caiu a 30.000. Encolhida e destruída, Roma não tinha nem os fundos para sustentar bibliotecas nem público para utilizá-las. ${ }^{27}$

A narrativa central da história da filosofia é aquela que a conecta com a história das bibliotecas e com a história da difusão da escrita, mas também com outras mudanças não diretamente ligadas à atividade intelectual, que são,

26 "Nós temos [...] muitos objetos domésticos [da Antiguidade e da Alta Idade Media]. Eles são uma importante fonte de letras e nomes rabiscados do período romano, assim como de eventuais mensagens [...]. Na alta IM, estes objetos são quase sempre mudos. Eles têm eventualmente o nome gravado, mas quase sempre de maneira muito limpa, sugerindo que foram aplicados com muito cuidado, talvez mesmo por um especialista na escrita, e não pelos proprietários eles mesmos. [...] Em um mundo muito mais simples, a necessidade urgente de ler e escrever diminui, e com ela a pressão social para a elite ser letrada. A difusão da cultura letrada no Ocidente pós-romano está definitivamente confinada ao clero. Uma análise detalhada de quase 1000 assinaturas em contratos na Itália do século VIII mostra que pouco menos de um terço era capaz de escrever seu nome, o resto fazendo apenas uma marca (identificada pelo escriba do contrato). A grande maioria do que sabia assinar pertencia ao clero (71\%). Dos 633 leigos, apenas 93, ou 14\%, escreveram seu próprio nome. Como testemunhos de contratos eram geralmente pessoas "importantes" da sociedade local, e como escrever o próprio nome não requer habilidades literárias muito grandes, estes números sugerem que mesmo o letramento mais básico era raro no público laico como um todo" (Ward-Perkins, 2006, p. 166). Michael Clanchy propõe uma visão mais positiva da difusão do letramento na Inglaterra a partir do século XI, notando, por exemplo, que a capacidade de ler pode ser mais difundida do que a de escrever, e descrevendo seu crescimento "a partir da burocracia, mais do que por algum desejo abstrato pela educação e pela literatura" (Clanchy, 1993², p. 19). Mesmo com esta correção, ele descreve o ressurgimento do letramento da partir do século XI, muito distante, portanto, do final da Antiguidade tardia.

27 Casson, 2001, p. 137. Deve-se contrastar ainda o tamanho da biblioteca do monastério de Patmos que contava, em 1201, com 330 livros (Casson, 2001, p. 142), ou aquela da Abadia de Corbie, com cerca de 300 livros no século IX (Smith, 2005, p. 49) - monastérios importantes na retomada da atividade filosófica no Ocidente -, com bibliotecas do mundo antigo, não apenas a célebre biblioteca de Alexandra, com 490.000 volumes na biblioteca principal e 42.800, na biblioteca secundária (Casson, 2001, p. 36), mas ainda com bibliotecas de cidades provinciais, como Herculano, cuja Villa dei Papiri contém cerca de 1.800 papiros (Casson, 2001, p. 74). Não é apenas o tamanho que importa, mas também a diversidade: enquanto dos 330 livros de Patmos, 314 eram de teologia (Casson, 2001, p. 142), a biblioteca romana de Varro continha "livros e monografias sobre todos os temas possíveis - agricultura, a língua latina, a história do povo romano, religião, filosofia, geografia, tecnologia” (Casson, 2001, p. 70). 
no entanto, partes das mudanças na Europa entre o fim do Império Romano e os séculos centrais da Idade Média. ${ }^{28}$ Podemos reformular a tese central deste artigo de maneira negativa: considerar Agostinho como um filósofo medieval significa separar a história da filosofia das histórias política, cultural e econômica, ou ainda das histórias das bibliotecas, das cidades, do letramento etc. O quadro geral de compreensão da história da filosofia é o da translatio studiorum, como propõe De Libera, não porque devemos comprar o aparato ideológico que forjou este tipo de tema na Idade Média, mas porque ele nos leva a considerar os movimentos culturais amplos nos quais a filosofia se constrói e o modo como eles são pensados em cada época. ${ }^{29}$ Esta é a importância crucial do tema da translatio studiorum na história da filosofia: considerar a história da filosofia como parte da história da cultura.

Para cada um dos pontos (i)-(iv) apontados acima, não há apenas um enorme hiato que se abre entre o mundo de Agostinho e Boécio e aquele de Abelardo e Tomás. A dinâmica que os explica foi desencadeada por acontecimentos que, como diz Wickham, "não eram inevitáveis e não foram percebidos como tais por aqueles que os viveram" (Wickham, 2009, p. 79). Parece difícil pensar que a forma que a filosofia tomou no século XIII estivesse de algum modo contida na filosofia do século $\mathrm{V}$, supondo que haja algum sentido em dizer isso. De maneira talvez menos metafórica: o conjunto de acontecimentos que levam aos traços (i)-(iv) se explica pelo virtual desaparecimento e pelo ressurgimento da atividade letrada em geral, que não podem ser explicados por elementos já existentes no século V. Como pensar, por exemplo, que a dinâmica linguística do Ocidente medieval, ou as associações entre pares que marcam o surgimento da universidade, ou mesmo a forma particular de transmissão da filosofia grega, na qual comentários de filósofos muçulmanos têm um papel central, estivessem de alguma forma presentes no Ocidente do século V? Como negar, por outro lado, que estes elementos sejam constitutivos da história da filosofia medieval?

A sugestão não é então que exista apenas uma história a ser contada acerca da filosofia entre os séculos I e XIII, mas que existe uma narrativa central para este período e que esta narrativa coloca Agostinho como parte da

28 Para uma visão geral das mudanças radicais que se seguiram à queda do Império Romano do ocidente, ver Ward-Perkins, 2006.

29 'A ideia da 'translação dos estudos', evidentemente associada à 'translação do Império', foi um poderoso instrumento da propaganda ocidental cristã, na época de Carlos Magno e do reino da França [...] De qualquer modo, ideológica ou não, a noção de 'translação dos centros de estudo' tem inegável valor para pensar a história da filosofia nos confins da Antiguidade tardia e da Idade Média, e posteriormente. Com efeito, esta translação permite expressar ao mesmo tempo a realidade e sua distorção" (De Libera, 1999 (1993), pp. 15-17). 
filosofia antiga. Esta narrativa é aquela que coloca a filosofia como parte da história geral e leva a uma periodização que é compatível com outros traços da história europeia.

\section{$\mathbf{V}$}

Mas será que não se pode propor outra caracterização de uma mudança de época na filosofia? Blumenberg dá uma resposta deste tipo. Segundo ele, "a formação da Idade Média só pode ser compreendida como uma tentativa de proteção definitiva contra a síndrome gnóstica” (Blumenberg, 1999 (1988²), p. 141). A tese é que há um princípio teórico central, ou um pequeno conjunto de princípios que unifica e dá o significado a toda uma época. No caso da IM, este princípio é, segundo Blumenberg, a resposta agostiniana ao problema do mal no mundo levantado pela Gnose: Agostinho tomou uma decisão para a IM, a de situar o mal no homem, não no mundo. ${ }^{30}$ Seele segue este tipo de abordagem. Como se poderia esperar, a vida atribulada de Agostinho, em particular a passagem do Maniqueísmo ao Cristianismo, representa precisamente esta escolha. A conversão de Agostinho é, assim, um marco fundamental de mudança de época, uma mudança no mundo interior que espelha e explica a mudança no mundo exterior. Com esta posição, Agostinho se torna um intérprete central e uma marca da passagem do mundo Antigo para o mundo medieval. ${ }^{31}$

Podemos explicar a transição da filosofia antiga à filosofia medieval a partir de uma escolha deste tipo? Vamos redescrever os quatro pontos expostos acima:

(i) o lugar da filosofia na cultura: a localização mais restrita da filosofia na cultura a partir do século XI (ou antes) e sua absorção no quadro universitário no século XIII, em oposição à presença mais diversificada da filosofia na cultura na Antiguidade tardia e à ausência de um quadro institucional tão bem delimitado e central;

(ii) a relação entre filosofia e religião: a onipresença da Igreja católica em virtualmente toda a atividade filosófica e a ausência de uma

30 "A resposta que Agostinho havia dado à questão [do Mal] foi a que teve mais conseqüências dentre as decisões que ele tomou para a IM" (Blumenberg, 1999 (1988²), p. 143).

31 "Agostinho representa, aí, aquele caso especial, que é constitutivo para a afirmação das transições, na medida em que ele criou, por um lado, algo novo no pensamento e na linguagem, mas se tornou, para além dessa ruptura com o que era conhecido pela Idade Média europeia, o mediador e intérprete central da filosofia antiga" (Seele, 2008, p. 249). 
alternativa a ser cristão, em oposição à diversidade do "Platonismo Cristão" da Antiguidade tardia e, claro, à possibilidade de não ser cristão;

(iii) a evolução dos temas filosóficos decorrendo das diferentes levas de textos disponíveis, em oposição à relativa continuidade da atividade filosófica no mundo antigo;

(iv) a língua da filosofia: o contraste entre as línguas vernaculares e línguas de referência, em particular, para o ocidente, o latim, que dá uma forma muito particular à linguagem filosófica, em oposição ao latim como língua vernacular para Agostinho.

Nenhum desses traços pode ser explicado ou previsto a partir de decisões teóricas que Agostinho ou outro filósofo qualquer pode ter tomado - a se supor que 'decisão' seja um termo adequado aqui. Se estes forem elementos que esperamos categorizar numa periodização filosófica, Blumenberg e Seele não têm as categorias adequadas para fazê-lo.

O modelo de Blumenberg não é adequado porque ele não capta as dinâmicas culturais que são pertinentes para a explicação do desenvolvimento da atividade filosófica. Inicialmente, mesmo se nos concentrarmos numa explicação puramente temática da história da filosofia, a sugestão que "decisões" agostinianas sejam decisivas não é correta em muitos casos. Agostinho não tem papel algum, por exemplo, no desenvolvimento da teoria da suposição, um produto tão importante quanto típico da filosofia medieval. Ele não é central tampouco na também típica e importante querela dos Universais. Na longa narrativa deste problema por De Libera, Agostinho é muito pouco presente; no index nominum da "Querelle des Universaux", o Bispo de Hipona tem menos da metade de entradas de Averróis e Boécio e menos de um terço de Avicena e Porfírio; no "L'Art des Généralités" são meras duas entradas. No domínio da lógica modal, Simo Knuuttila diz que Agostinho adere à compreensão estatística das modalidades, e que a ideia de possíveis não realizados aparece de maneira marginal em sua teoria. ${ }^{32}$ Este domínio é crucial porque ele é parte central do problema que, segundo Blumenberg, marca a passagem da filosofia

32 "Seguindo a tradição platônica, Agostinho pensava que as formas genéricas do ser pertenciam a uma escala perfeita e que Deus não deixa parte alguma irrealizada. Neste sentido, ele afirmava uma equivalência entre possibilidades e suas realizações, i.e., ele aceitava uma forma da ideia chamada por Lovejoy de "princípio de plenitude". No entanto, ele também dizia que algumas possibilidades divinas nunca são realizadas. Embora este ponto de vista fique na periferia de seu pensamento, ela é historicamente importante, porque motivou teólogos posteriores a repensarem o significado de noções modais" (Knuuttila, 1993, p. 68). 
medieval à filosofia moderna. Nesse caso, Agostinho desempenha um papel mais importante do que nos exemplos anteriores, mas que ainda fica aquém da ideia de possibilidades sincrônicas, tão importante a partir do final do século XIII. De qualquer modo, não tem sentido falar-se em decisão, se por isso se quer dizer que uma posição teórica sua determinou desenvolvimentos teóricos posteriores (e este é o único modo que consigo entender esta posição). Cada filósofo representa um elo numa complexa história. Knuuttila sugere que Agostinho deu um passo importante numa longa história que levará à aceitação plena de uma nova concepção de modalidades apenas no século XIII - não se trata, portanto, de alguma "decisão" que ele tenha tomado.

Mas mesmo esta descrição é enganadora. Agostinho não tomou a decisão constitutiva da IM não porque outro pensador o tenha feito - ninguém o fez. Esta ideia não tem utilidade alguma na explicação da dinâmica descrita parcialmente nos traços acima, são as "condições textuais" que levam teorias de um ponto a outro, e estas condições são apenas parcialmente explicadas, se tanto, por aspectos eles mesmos teóricos. Escolhas teóricas de um filósofo só têm importância para a periodização filosófica se elas forem assumidas nos movimentos que explicam dinâmicas mais amplas de transmissão de problemas filosóficos.

\section{VI}

O que devemos buscar então? Minha sugestão é que devemos buscar, inicialmente, os mecanismos de transmissão e estabilidade de teses e temas filosóficos. Vou fazer muito brevemente uma proposta que visa inserir a história da filosofia no quadro geral de transmissão de ideias e, em seguida, propor como este quadro geral pode auxiliar na compreensão do que pode ser captado por sua periodização.

Um modelo de tratamento que me parece frutífero é o da epidemiologia de representações, proposto por Dan Sperber. A ideia é buscar a explicação do surgimento, da expansão, da fusão, da divisão e da morte de estirpes de representações em fatores que explicam sua transmissão de indivíduo a indivíduo. A primeira observação é que buscamos a explicação de por que indivíduos aceitam determinada teoria, ou antes por que eles têm a oportunidade de aceitar determinada teoria. Lembremos que um dos aspectos cruciais que separa Agostinho de filósofos dos séculos XII e XIII é que ele pôde aceitar teorias não cristãs, o que não é o caso de Tomás de Aquino e Abelardo. 
A diferença se situa nos ambientes nos quais diferentes ideias circulam. Esta dinâmica pode ser pelo menos parcialmente explicada pelo que Sperber descreve como os fatores ambientais, que incluem

[...] as recorrências de situações nas quais a representação leva ou contribui para a ação apropriada, a disponibilidade de fontes externas de memória (em particular escritas) e a existência de instituições que se dedicam à transmissão da representação. (Sperber, 1996, p. 84)

Enunciada de maneira direta, eis a sugestão: as teses filosóficas discutidas e aceitas tipicamente por filósofos medievais são aquelas cuja aceitação é promovida por instituições dedicadas a sua transmissão, que estão representadas em textos disponíveis a estes filósofos e cuja defesa é aceita, ou cuja recusa é penalizada, nos contextos nos quais se encontram esses filósofos.

Uma vez que se coloca a questão desse modo, parece claro que os fatores ambientais de difusão de representações filosóficas mudam entre os séculos V e XI nestas três dimensões: (i) o que conta como uma ação apropriada, (ii) a existência de instituições dedicadas à transmissão de ideias e (iii) a disponibilidade de fontes externas.

(i) A aceitação de ideias não cristãs é um caminho aberto no tempo de Agostinho, caminho que ele mesmo percorreu. Este caminho já está fechado há muito no Ocidente no século XI. Se é claro que no XIII no Ocidente não era dada a um filósofo a possibilidade de não ser cristão, versões alternativas do cristianismo mesmo eram combatidas, o que seleciona as ações adequadas em cada contexto. Luca Bianchi escreve assim sobre a censura na universidade medieval:

Os filósofos e teólogos que trabalhavam em Paris eram submetidos a entraves muito mais numerosos e diversos do que normalmente se imagina. (Bianchi, 1999, p. 13) A luta contra as heresias nos meios acadêmicos é apenas um aspecto de um fenômeno muito mais amplo, a repressão a toda forma de dissidência intelectual. O que caracteriza a censura nos séculos XIII e XIV é justamente a ampliação da esfera de ação. (Bianchi, 1999, p. 15)

Olivier Morin observa, assim, como a motivação para a transmissão é um fator para a transmissão de saberes. ${ }^{33}$ Um aspecto da motivação se situa no ambiente que penaliza ou premia a transmissão ou, ao contrário, sua não

33 "Ao se ler os trabalhos dos historiadores das ciências que se ocuparam da evolução dos saberes antes da Idade Média, é notável o número de começos infrutíferos (faux départs) e de descobertas que a nada levaram, porque não existia a vontade de transmissão (mesmo se todas as outras condições estavam reunidas)" (Morin, 2011, p. 188). 
transmissão, mas também que os indivíduos pensem que devem ou podem fazê-lo.

(ii) As instituições dedicadas à transmissão de textos são muito distintas entre os séculos $\mathrm{V}$ e o que se desenha a partir do século XI. Como já observamos, há uma enorme diferença entre as bibliotecas no mundo antigo e no início da IM. A Universidade, que desempenhará um papel central no século XIII, com suas tensões entre o controle pela Igreja e a vontade dos mestres de abertura ao novo, com a diversidade de estudantes e professores vindos de toda a Europa, com a forma tão rígida de seu ensino e, consequentemente, de seus textos, simplesmente inexiste na Antiguidade Tardia. A educação pagã que Agostinho recebeu teria sido impossível nos séculos XII ou XIII. ${ }^{34}$ As instituições respondem por um aspecto crucial na transmissão de tradições, a robustez:

Sabemos que a redundância e a repetição podem estabilizar tradições mesmo quando a transmissão não é muito fiel. Uma certa dose de repetição e redundância é mesmo indispensável: se um item cultural só pode ser apreendido de um único modelo, em uma vez, ele desaparecerá, mesmo se representar uma vantagem adaptativa para os que o adotarem, e mesmo se ele puder ser recuperado facilmente por um aprendizado individual (Morin, 2011, p. 139).

Reconhecemos aqui, por um lado, como a transmissão de temas filosóficos pôde se interromper em torno do século $\mathrm{V}$, mas também como a existência de instituições, como a universidade, desempenha um papel central na estabilização de tradições filosóficas a partir do século XIII.

(iii) Os textos disponíveis também são muito diferentes num caso e no outro - não apenas aqueles que Agostinho de fato leu, mas aqueles que estavam disponíveis a seus contemporâneos que liam grego. A filosofia medieval se forja, entre os séculos XI e XIII, pelo ritmo de chegada de traduções de textos gregos e de seus comentadores dos mundos grego e árabe. Boécio, um pouco posterior a Agostinho, é precisamente um dos tradutores de alguns dos textos mais importantes para a IM e está num mundo no qual a literatura grega está disponível e tem leitores - estas duas condições, claro, não são independentes.

Minha sugestão é que o que explica o surgimento de estirpes de representações propriamente medievais, que são versões mais ou menos estáveis de estirpes de representações gregas ou monoteístas, com um grau 
de especificidade própria que merece uma divisão histórica, são precisamente estas mudanças nas condições de transmissão de ideias.

Esta associação é compatível com a experiência do historiador da filosofia medieval, que não apenas reconhece estes três fatores ambientais como típicos da Idade Média, diferentes dos ambientes que a precedem e que se seguem a ela, como é capaz de reconhecer o misto de continuidade e rupturas das quais ela se faz. Fatores ambientais explicam, inicialmente, a profunda ruptura que se desenha desde o final do século $V$ e explicam também quais representações filosóficas serão retomadas a partir do século IX. A identificação puramente abstrata de teses filosóficas, como fazem Marrone, Blumenberg e Steele, não é suficiente para explicar este padrão de continuidades e rupturas. Também não chega a ser surpreendente que uma periodização histórica seja sensível a um acontecimento do porte da queda do Império Romano do ocidente.

A separação entre o mundo antigo e o mundo medieval não é um teste interessante para esta sugestão acerca da periodização em história da filosofia. A diferença entre estes momentos na história do ocidente é muito grande, talvez seja mais importante perguntar por que razão se pôde perder uma fronteira tão evidente, i.e., por que se pode considerar Agostinho um filósofo medieval. Interessa mais buscar o que a tese de Sperber poderia nos dizer sobre a passagem da filosofia medieval ao Renascimento e à filosofia moderna. Aqui serei muito breve. Retomemos os traços centrais que caracterizam ambientes de difusão de ideias: (i) o que conta como uma ação apropriada, (ii) a disponibilidade de fontes externas e (iii) a existência de instituições dedicadas à transmissão de ideias. Nessas três dimensões, também mudanças importantes começam a ocorrer a partir do século XIV e, de maneira mais clara, do século XV em diante. Inicialmente, a possibilidade de uma atividade intelectual fora do controle da Igreja aumenta, o que aumenta o espaço das ações apropriadas. Há uma maior disponibilidade de fontes externas, tanto pela tradução de novos textos antigos quanto pela circulação de textos contemporâneos também fora do controle universitário. Finalmente, a modificação do ambiente institucional ele mesmo, em particular pela possibilidade da existência de uma atividade intelectual fora da universidade. ${ }^{35}$

35 Hankins dá uma descrição desta história que ilustra muitos destes pontos: "Da segunda metade do século XIV em diante, a justificação intelectual e moral da filosofia na cultura cristã estava mudando, tornando-se menos vital para sua sobrevivência. Enquanto disciplina, a filosofia estava se tornando progressivamente mais autônoma, tanto institucionalmente quando intelectualmente, era cada vez mais comum que mestres passassem toda sua carreira ensinando filosofia e temas correlatos nas faculdades de artes e medicina. [...] O prestígio pessoal de alguns filósofos famosos era tanto que colégios e conselhos de cidadãos que contratavam filósofos estavam dispostos a considerar preocupações relativas à ortodoxia como irrelevantes para as necessidades reais dos estudantes. Na Itália, universidades eram instituições 
O que há de particular agora é que esta mudança coincide temporalmente com uma filosofia que ainda se desenvolve dentro dos condicionamentos próprios da filosofia medieval, a assim chamada escolástica tardia. Aqui há de fato um problema de periodização: será que Montaigne (1533-1592) e Pedro da Fonseca (1528-1599) pertencem à mesma época filosófica? E o que dizer de Descartes (1596-1650) e João Poinsot (1589-1644)? Talvez aqui deixe de fazer sentido falar de épocas diferentes e o interesse da aplicação dos mecanismos propostos por Sperber apareça mais claramente. Por um lado, há uma grande continuidade de problemas entre a filosofia tardo-medieval e a primeira filosofia moderna, que depende da continuidade das condições textuais. ${ }^{36}$ Por outro lado, há uma não menos clara diferença em muitos dos mecanismos que garantem esta transmissão - o leitor a quem os textos filosóficos são dirigidos, as instituições nas quais se encontram seus autores, as línguas nas quais escrevem etc. Uma vez que temos ferramentas mais finas de compreensão das modificações da história da filosofia, podemos evitar classificações estanques que tornariam opacas estas continuidades, como alertam Dominik Perler (2008) e Robert Pasnau (2011, pp. 1-5) sem perder as mudanças nas condições da atividade filosófica que classificações históricas buscam captar.

Há outro aspecto importante que deve ser trazido à baila aqui. Ambientes de difusão de ideias são parcialmente constituídos pelas ideias elas mesmas acerca do que deve ser aceito ou não - o que conta ou não como uma ação apropriada, assim como o que motiva a criação de instituições e a busca de fontes que garantem a transmissão destas ideias. Talvez parte do que ocorra a partir do século XV seja uma mudança no que Sperber chama de "crenças reflexivas", que são aceitas "em virtude de crenças de segunda ordem sobre as crenças elas mesmas" (Sperber, 1996, p. 89).

Como se poderia esperar, fatores psicológicos e ambientais são eles mesmos afetados pela distribuição de representações. Representações previamente internalizadas são

cívicas sobre as quais as autoridades religiosas tinham pouco poder real e as carreiras na medicina e no direito civil eram muito menos dependentes do incentivo da Igreja do que na Europa do norte. O que contava para a contratação de professores era seu conhecimento e sua capacidade de trazer prestígio para a universidade. Esta atitude era favorecida pelo fato do número de universidades estar crescendo exponencialmente a partir do final do século XIV. A riqueza pessoal maior, a fama, a segurança institucional e a independência das pressões eclesiásticas facilitou aos filósofos desenvolverem sua própria posição com maior liberdade. Assim, durante o Renascimento, uma ampla gama de posições filosóficas se expressaram, algumas compatíveis com a doutrina cristã, outras não. Algumas surgiram do estudo renovado de Averróis, outras do estudo de novas fontes filosóficas que os humanistas tornaram disponíveis, como os antigos comentadores gregos de Aristóteles, outras a partir de novas traduções humanistas de Aristóteles. A filosofia estava surgindo como uma disciplina secular" (Hankins, 2007, p. 39).

36 Ver o excepcional trabalho de Pasnau (2011), que mostra em detalhes a continuidade de diversas discussões metafísicas entre os séculos XIII e XVII. 
um fator chave na susceptibilidade que uma pessoa tem para novas representações. $\mathrm{O}$ ambiente humano é, em grande medida, feito pelo homem, e feito a partir de representações culturais. Como consequência, a retroalimentação (feedback loops) deve ser esperada tanto em modelos que explicam famílias particulares [de representações] quanto entre modelos. A complexidade resultante é ecológica, mais do que orgânica. (Sperber, 1996, pp. 83-84)

Por que uma tese deve ser aceita? O fato de ela ser uma tese cristã, ou aprovada pela Igreja, ou aristotélica, é um fator para sua recusa ou para sua aceitação? Parece que parte do que está em jogo na passagem da filosofia medieval à filosofia moderna - muito mais complicada e nuançada do que a transição que nos ocupa - é precisamente que diferentes grupos sociais passaram a dar respostas diferentes a estas perguntas, mesmo quando defendem teses próximas, e, portanto, a selecionar de maneira diferente quais ideias que devem ser difundidas e de que modo.

\section{VII}

Como fatos tão conhecidos podem dar lugar a respostas opostas em relação à pergunta "é Agostinho um filósofo medieval?". A razão é que as perguntas feitas são na verdade distintas. A classificação de Agostinho como um filósofo medieval vem da resposta à pergunta sobre como as diferentes filosofias gregas foram absorvidas no quadro de religiões monoteístas - dito de outro modo, é uma pergunta acerca da formação de um sistema de crenças. Nesse caso, Agostinho desempenha sem dúvida um papel central. Podemos chamar esta pergunta o "modelo teórico de periodização em história da filosofia", já que ele identifica uma época - a medieval - por um problema, ou um pequeno conjunto de problemas, que pode ser descrito teoricamente. É claro que existe aqui uma história a ser contada; no entanto, por pelo menos duas razões, devemos resistir a utilizá-la como a narrativa central a identificar o período medieval.

Inicialmente, a história da absorção da filosofia grega num quadro cristão faz mais sentido se considerarmos as três religiões monoteístas como tendo um conjunto de problemas comuns a resolver, cujas soluções influenciam umas às outras: isto é claro pela prolongação de discussões que surgiram na Antiguidade Tardia e no Islã no Ocidente cristão, mas também pela participação de pensadores judeus, como Filo de Alexandria e Maimônides. Ora, esta história cobre momentos muitos distintos e lugares diferentes. Por um lado, não parece razoável pensar que um mesmo período histórico cubra a Alexandria do século I, Bagdá do século X e Paris do século XIII. Por outro lado, escolher apenas 
parte desta história, digamos, apenas a sua face cristã, não faz sentido, se o que nos interessa é a constituição de um determinado sistema de crenças. Esta última observação deve ser clara a qualquer um que tenha familiaridade com os textos de filósofos do século XIII, recheados de referências a filósofos islâmicos; este é o caso, por exemplo, de "De ente et essentia", de Tomás de Aquino, que tanto deve, a começar pela distinção que lhe dá o título, ao persa muçulmano Avicena. Exemplos desse tipo poderiam ser multiplicados.

A segunda razão para se recusar esta classificação é mais importante. Ao buscar uma periodização na história da filosofia, devemos buscar o que explica quando e como o que conta como filosofia parece mudar, quando e como a linguagem mesma da filosofia, quando não sua língua, parece ser outra - o que sentimos na passagem da filosofia medieval para a filosofia moderna, por exemplo. Bem, parece-me que este tipo de mudança ocorre entre o século IV e o século XIII, como procurei argumentar acima, mas dizer isso é uma petição de princípio. Minha sugestão é que mudanças desse tipo não se explicam pela execução de algum projeto teórico, não importa qual seja sua centralidade na cultura. O que explica mudanças desse tipo?

Expus acima minha hipótese sobre essas mudanças, utilizando o quadro teórico de Sperber, para explicar como as ideias filosóficas se difundem ao longo do espaço e do tempo e como esta dinâmica de difusão de ideias conheceu uma ruptura crucial com o fim do mundo antigo. Gostaria de propor uma apresentação mais neutra das razões para a recusa deste modelo teórico de periodização da filosofia, que pode ser apresentada por outra pergunta: como a história da filosofia é parte da história da cultura? É precisamente esta pergunta cuja resposta coloca Agostinho do lado da filosofia antiga, e não da filosofia medieval. Uma vez que colocamos a pergunta dessa maneira, a resposta é que a filosofia faz parte da história da cultura porque os mecanismos de transmissão, de estabilidade e transformação dependem dos mesmos fatores que explicam a transmissão e a estabilidade de outras formas culturais: o que está disponível, de que modo, qual a motivação para transmissão de seus textos, em suma, pelos mecanismos de transmissão de tradições humanas. A narrativa central que fornece a periodização na história da filosofia é precisamente aquela que a torna parte da história da cultura.

Por que é importante compreender que Agostinho é um filósofo medieval? Bem, inicialmente, para que a resposta a esta pergunta não é importante: ela não tem importância alguma para compreender Agostinho ele mesmo. ${ }^{37} \mathrm{O}$ se definir um período [i.e., a filosofia medieval], fazer distinções estanques entre diferentes períodos e 
trabalho do intérprete permanece o mesmo, qualquer que seja a resposta que dê a essa pergunta: ele ainda trabalha sobre os mesmos textos, avalia as fontes de Agostinho, com quem estudou etc. A principal razão de se compreender que Agostinho é um filósofo antigo, e não medieval, é ver que a filosofia é parte da cultura e sua periodização não pode ser tão estranha ao conjunto de fenômenos culturais do qual ela faz parte. ${ }^{38}$

\section{Referências}

ARMSTRONG, A. H. "Preface, Introduction". In: A. H. Armstrong (ed.). The Cambridge history of later greek and early medieval philosophy. Cambridge: Cambridge University Press, 1967. pp. xiv-xv, 1-9.

BIANCHI, L. "Censure et liberté intellectuelle à l'Université de Paris (XIII-XIV siècles)". Paris: Les Belles Lettres, 1999.

BLUMENBERG, H. "La Légitimité des Temps Modernes". Paris: Gallimard, 1999 $\left(1988^{2}\right)$.

BROWN, P. “Augustine of Hippo - a Biography”. Berkeley-Los Angeles: University of California Press, 2000 (1967).

CASSON, L. "Libraries in the Ancient World". New Haven: Yale University Press, 2001.

CLANCHY, M. "From Memory to Written Record". Londres: Blackwell, 1993².

DE LIBERA, A. “A Filosofia Medieval”. Rio de Janeiro: Jorge Zahar, 1990 (1989).

DE LIBERA, A. "Penser au Moyen Age". Paris: Seuil, 1991.

DE LIBERA, A. "La Philosophie Médiévale”. Paris: PUF, 1993.

DE LIBERA, A. "La Querelle des Universaux”. Paris: Seuil, 1996.

DE LIBERA, A. "L'Art des Généralités". Paris: Aubier, 1999.

EVANS, G. R. "Philosophy and Theology in the Middle Ages". Londres: Routledge, 1993.

procurar por etiquetas sob as quais autores de uma dada época podem ser classificados é inútil. Devese antes olhar para cada autor individualmente e perguntar como ele lidou com problemas específicos dentro do quadro teórico do seu tempo" (Perler, 2008, p. 229). Parece-me, no entanto, que a lição não é abandonar toda categorização histórica, como parece sugerir Pasnau (2011,3n), mas compreender que tipo de explicação as categorias historiográficas podem fornecer: não chaves de leitura para filósofos individuais, mas uma narrativa das transformações pelas quais a filosofia passou ao longo dos séculos.

$38 \mathrm{O}$ argumento que apresentei neste artigo surgiu ao longo dos anos como aula introdutória da disciplina História da Filosofia Medieval, no curso de graduação em Filosofia da UFMG. Procurei articular de maneira mais precisa o argumento para o colóquio do CEPAME realizado em novembro de 2012, na USP. Agradeço aos alunos que escutaram estas ideias em suas diferentes versões e à audiência do colóquio pelo interesse e pelo ceticismo quanto à relevância da pergunta que procurei responder, assim como quanto à resposta que propus. Ambos me fizeram buscar uma formulação mais precisa para o argumento. Agradeço ainda Claude Panaccio, Henrique Estrada Rodrigues, Katharine Tachau e Newton Bignotto, pela paciência em ler o texto, pelas sugestões e pelo estímulo. Finalmente, agradeço ao CNPq, pelo apoio recebido. 
FLASCH, K. "Introduction à la Philosophie Médiévale". Paris: Flammarion, 1992 (1987).

GAUVARD, C.; DE LIBERA, A.; ZINK, M. (eds.). "Dictionnaire du Moyen Âge". Paris: PUF, 2002.

GRÉVIN, B. "Le Parchemin des Cieux - Essai sur le Moyen Age du langage". Paris: Seuil, 2012.

HAMILTON, B. "Religion and the laity". In: D. Luscombe e J. Riley-Smith (eds.). The New Cambridge Medieval History IV - c. 1024 - c. 1198 (part I). Cambridge: Cambridge University Press, 2008a. pp. 461-498.

HAMILTON, B. "The Albigensian Crusade and heresy". In: D. Abulafia (ed.). The New Cambridge Medieval History $V-c .1198-c .1300$. Cambridge: Cambridge University Press. 2008b. pp. 164-203.

HANKINS, J. "Humanism, scholasticism and Renaissance philosophy". In: J. Hankins (ed.). The Cambridge Companion to Renaissance Philosophy. Cambridge: Cambridge University Press. 2007. pp. 30-48.

KENNY, A. "Uma Nova História da Filosofia Ocidental”. Vol. II - Filosofia Medieval, São Paulo: Loyola, 2008 (2005).

KNUUTTILA, S. "Modalities in Medieval Philosophy". Londres: Routledge, 1993.

LAGERLUND, H. (ed.). "Encyclopedia of Medieval Philosophy - Philosophy between 500-1500". Dordrecth: Springer, 2011.

LLOYD, A. C. "Introduction to later Neoplatonism". In: A. H. Armstrong (ed.). The Cambridge history of later greek and early medieval philosophy. Cambridge: Cambridge University Press, 1967. pp. 272-282.

LIEBESCHÜTZ, H. "Boethius and the legacy of antiquity". In: A. H. Armstrong (ed.). The Cambridge history of later greek and early medieval philosophy. Cambridge: Cambridge University Press, 1967. pp. 538-564.

MARENBON, J. "Early Medieval Philosophy (480-1150)". Londres: Routledge, 1983.

MARKUS, R. A. "Marius Vitorinus and Augustine". In: A. H. Armstrong (ed.). The Cambridge history of later greek and early medieval philosophy. Cambridge: Cambridge University Press, 1967. pp. 331-423.

MARRONE, S. "Medieval Philosophy in Context". In: A. S. McGrade (ed.). The Cambridge Companion to Medieval Philosophy. Cambridge: Cambridge University Press, 2003. pp. 10-50.

MARROU, H.-I. “Décadence romaine ou antiquité tardive?”. Paris: Seuil, 1977. MARTIN, C. "An Introduction to Medieval Philosophy". Edinburgh: Edinburgh University Press, 1996.

MOORHEAD, J. "Boethius' life and the world of late antique philosophy". In: J. Marenbon (ed.). The Cambridge Companion to Boethius. Cambridge: Cambridge University Press, 2009. pp. 13-33.

MORIN, O. "Comment les traditions naissent et meurent”. Paris: Seuil, 2011. 
PASNAU, R. "Introduction". In: R. Pasnau, Ch. Van Dyke (eds.). The Cambridge History of Medieval Philosophy. Cambridge: Cambridge University Press, 2010. pp. $1-10$.

PASNAU, R. "Metaphysical Themes - 1274-1671”. Oxford: Oxford University Press, 2011.

PERLER, D. "Introduction”. Vivarium, 46, pp. 223-231, 2008.

SEELE, P. "Philosophie der Epochenschwelle - Augustin zwischen Antike und Mittelalter". Berlin: Walter de Gruyter, 2008.

SHEPPARD, A. "Philosophy and Philosophical Schools". In: A. Cameron et al. (eds.). The Cambridge Ancient History - v. XIV: Empire and Successors, A.D. 425600. 2000. p. 835-854.

SMITH, J. M. H. "Europe after Rome". Oxford: Oxford University Press, 2005.

SPERBER, D. "Explaining Culture - a naturalistic approach". Oxford: Blackwell, 1996.

VERGER, J. "L'Essor des Universités au XIII" siècle”. Paris: Cerf, 1997.

VEYNE, P. "Quand notre monde est devenu chrétien" (312-394). Paris: Albin Michel, 2007.

WARD-PERKINS, B. "The Fall of Rome”. Oxford: Oxford University Press, 2006.

WICKHAM, C. "The Inheritance of Rome". Londres: Penguin, 2009.

WOOD, I. "Culture". In: R. Mckitterick (ed.). Short Oxford History of Europe - The Early Middle Ages. Oxford: Oxford University Press, 2001. pp. 167-198. 